\title{
Trabalho rural e riscos à saúde: uma revisão sobre o "uso seguro" de agrotóxicos no Brasil
}

\author{
Rural work and health risks: a review \\ into de "safe use" of pesticides in Brazil
}

Pedro Henrique Barbosa de Abreu ${ }^{1}$

Herling Gregorio Aguilar Alonzo ${ }^{1}$

${ }^{1}$ Programa de PósGraduação em Saúde

Coletiva, Departamento de Saúde Coletiva, Faculdade de Ciências Médicas, Universidade Estadual de Campinas. R. Tessália Vieira de Camargo 126, Cidade Universitária Zeferino Vaz. 13.083-887 Campinas SP Brasil.

pedro_hba@yahoo.com.br

\begin{abstract}
The paradigm of the "safe use" of pesticides is based on measures to control risks in the handling of these products. However, studies carried out in various regions of Brazil reveal a situation of widespread exposure and health damages among rural workers, revealing the ineffectiveness of this paradigm. This work presents a critical review of the "safe use" approach for pesticides in scientific papers published in Brazil in the past 15 years. Results indicate that these studies do not address, simultaneously, all the work activities that involve exposure and risk of intoxication (acquisition, transportation, storage, preparation and application, final disposal of empty containers and sanitization of contaminated clothes/ PPEs), nor do they comprehensively address the "safe use" measures recommended in safety manuals, which are mandatory for each activity. A total of 25 studies were selected and analyzed, revealing a high number of results and analyses regarding activities of preparation and application and $f i$ nal disposal of empty containers. The range of the approaches was seen to be timely in the six work activities. For future studies, a broader approach of the "safe use" of pesticides is recommended, seeking to reveal the complete infeasibility of this safety paradigm.
\end{abstract}

Key words Pesticides, Occupational risks, Environmental health, Public health surveillance
Resumo O paradigma do "uso seguro" de agrotóxicos sustenta-se em medidas de controle dos riscos na manipulação desses produtos. No entanto, estudos realizados em diversas regiões do País revelam um quadro de exposição e danos à saúde de trabalhadores rurais, evidenciando a ineficácia deste paradigma. Este trabalho apresenta uma revisão crítica sobre a abordagem do "uso seguro" de agrotóxicos nos artigos cientificos publicados nos últimos 15 anos no Brasil. Os resultados apontaram que esses estudos não abordam, simultaneamente, todas as atividades de trabalho que envolvem exposição e risco de intoxicação (aquisição, transporte, armazenamento, preparo e aplicação, destino final de embalagens vazias e lavagem de roupas/EPI contaminados), tampouco abordam de maneira abrangente as diversas medidas de "uso seguro", descritas pelos manuais de segurança, obrigatórias para cada atividade. No total, 25 artigos foram selecionados e analisados, evidenciando-se a concentração de resultados $e$ análises nas atividades de preparo e aplicação e destino final de embalagens vazias. A abrangência das abordagens se mostrou pontual nas seis atividades. Para futuros trabalhos, sugere-se uma abordagem ampliada do "uso seguro" de agrotóxicos, buscando-se revelar a completa inviabilidade deste paradigma de segurança.

Palavras-chave Agrotóxicos, Risco ocupacional, Saúde ambiental, Vigilância em saúde 


\section{Introdução}

Em 2013, a Associação Brasileira da Indústria Química (Abiquim) divulgou um aumento de $10,3 \%$ nas vendas de agrotóxicos no Brasil, atingindo movimentação de US\$ 9,4 bilhões em 2012, ante US\$ 8,5 bilhões em $2011^{1}$. Nos últimos 12 anos, o mercado brasileiro de agrotóxicos cresceu 190\%, tornando o País, desde 2008, o maior consumidor dessas substâncias no mun$\mathrm{do}^{2-4}$. O recorde de consumo de agrotóxicos e o contexto atual químico-dependente de produção de alimentos são reflexos da "modernização do campo" adotada pelo governo brasileiro, a partir da década de 1960, que modificou as práticas agrícolas no País ${ }^{5}$.

Essa modernização, através de transferência de tecnologia, foi financiada por instituições responsáveis pela expansão internacional de empresas estadunidenses - como a USAID, Rockfeller e Ford Foundation e o Banco Mundial - e foi denominada "revolução verde" pelo diretor da USAID, em $1968^{6}$. Dentro do pacote da "revolução verde" duas práticas se complementavam: a monocultura, que favorece a proliferação de "pragas agrícolas"7, e o uso intensivo de agrotóxicos, solução tecnológica para o controle dessas "pragas"8.

Para que o modelo agroquímico de produção se estabelecesse, foram adotadas no Brasil, entre as décadas de 1960 e 1980, medidas governamentais que, articuladas, impulsionaram o acesso de trabalhadores rurais aos agrotóxicos. Entre as principais estavam o Sistema Nacional de Crédito Rural, que atrelava o crédito rural à obrigatoriedade de compra de insumos químicos, e o Programa Nacional de Defensivos Agrícolas, que financiava a criação de empresas nacionais e a instalação de empresas transnacionais do setor no País. Mesmo estabelecido, este modelo recebe, até os dias de hoje, permanente apoio dos governos municipais, estaduais e federal, principalmente, através de isenções fiscais concedidas às indústrias químicas produtoras de agrotóxicos?.

Além desses subsídios, os custos sociais, sanitários e ambientais de curto, médio e longo prazos, gerados pela utilização intensiva de agrotóxicos, foram assumidos por toda a população, através de gastos públicos com a recuperação de áreas contaminadas, com o tratamento de intoxicações agudas e crônicas, afastamentos e aposentadorias por invalidez de trabalhadores rurais, além dos irreparáveis danos familiares causados pelas mortes decorrentes da utilização dessas substâncias. Soares e Porto ${ }^{10-12}$ utilizam o conceito de externalidade negativa para definir a socialização desses custos de responsabilidade direta das indústrias químicas, apontando que a não contabilização dos impactos negativos à saúde humana e ao meio ambiente, no preço final dos produtos agrotóxicos, associada ao apoio fiscal fornecido pelo Estado às indústrias químicas e ao discurso da indissociabilidade do aumento da produtividade e do uso de agroquímicos (sustentado pela bancada ruralista no Congresso Nacional), acaba por maquiar o custo real decorrente da utilização dessa tecnologia de controle de "pragas", e por subsidiar econômica e ideologicamente a decisão do agricultor em aderir ao modelo hegemônicoconvencional de produção.

Paralelamente às externalidades negativas, a resposta do governo brasileiro aos questionamentos internacionais e internos, sobre os impactos do uso intensivo de agrotóxicos, também atendeu aos interesses das indústrias químicas e, consequentemente, incentivou o modelo de produção baseado no uso de biocidas. A Lei $\mathrm{n}^{\circ}$ 7.802/1989 ${ }^{13}$, conhecida como Lei dos Agrotóxicos, o Decreto 4.074/2002 ${ }^{14}$ que a regulamenta, assim como a Norma Regulamentadora $n^{\circ} 31$ (NR 31$)^{15}$ do Ministério do Trabalho e Emprego (MTE), assumiram as diretrizes do Código Internacional de Conduta para a Distribuição e Uso de Agrotóxicos ${ }^{16}$ - elaborado pela Food and Agriculture Organization (FAO), órgão das Nações Unidas (ONU) para elaboração de políticas e diretrizes regulatórias em relação à produção de alimentos, em parceria com o International Group of National Associations of Agrochemical Manufacturers (GIFAP), associação das indústrias químicas responsável por garantir os interesses deste setor em âmbito internacional (renomeada para Global Crop Protection Federation, na década de 1980, e para Croplife International, na década de 1990) $)^{17,18}$ - como base conceitual ${ }^{19}$. Definiuse, assim, as responsabilidades de empregadores rurais e entes federados para o cumprimento e fiscalização de medidas de proteção ao invés de definir a priorização do Estado brasileiro, através de políticas públicas e incentivos econômicos, no desenvolvimento de tecnologias não químicas de controle de "pragas", como forma preventiva de mitigação dos danos provocados pela utilização de agrotóxicos. Desta forma, a efetividade do paradigma do "uso seguro" de agrotóxicos, desenvolvido pelas indústrias químicas, recai sobre a (in)capacidade do Estado brasileiro em fiscalizar e controlar as práticas de trabalho em todos os estabelecimentos rurais, assim como em garantir o treinamento de cada trabalhador rural que manipule essas substâncias ${ }^{19,20}$. 
Quadro 1. Resumo das medidas de "uso seguro" referentes às atividades de aquisição, transporte, armazenamento, preparo e aplicação, destino final das embalagens vazias e lavagem das roupas/EPI contaminados por agrotóxicos descritas nos manuais da ANDEF.

\begin{tabular}{|c|c|c|}
\hline Aquisição & Transporte & Armazenamento \\
\hline $\begin{array}{l}\text { Consultar Engenheiro } \\
\text { Agrônomo }\end{array}$ & $\begin{array}{l}\text { Verificar com o comerciante se } \\
\text { é necessário cuidado especial } \\
\text { para transportar os agrotóxicos } \\
\text { adquiridos }\end{array}$ & $\begin{array}{l}\text { Depósito deve ser separado de outras } \\
\text { construções e estar livre de inundações }\end{array}$ \\
\hline $\begin{array}{l}\text { Usar Receituário } \\
\text { Agronômico/ e guardar a } \\
\text { segunda via }\end{array}$ & $\begin{array}{l}\text { Verificar se a nota fiscal está } \\
\text { preenchida com as disposições } \\
\text { exigidas no Regulamento de } \\
\text { Transporte de Produtos Perigosos } \\
\text { (RTTP) }\end{array}$ & $\begin{array}{l}\text { Depósito deve estar a uma distância } \\
\text { mínima de } 30 \text { metros de fontes de água, } \\
\text { residências e instalações para animais }\end{array}$ \\
\hline $\begin{array}{l}\text { Exigir Nota Fiscal e } \\
\text { guardá-la para consultar } \\
\text { o endereço da unidade de } \\
\text { recebimento de embalagens } \\
\text { vazias }\end{array}$ & $\begin{array}{l}\text { Verificar se a Ficha de Emergência } \\
\text { e o Envelope de Transporte } \\
\text { acompanham a nota fiscal }\end{array}$ & $\begin{array}{l}\text { Construção de alvenaria, com piso } \\
\text { cimentado e telhado resistente, sem } \\
\text { goteiras }\end{array}$ \\
\hline $\begin{array}{l}\text { Aproveitar para comprar } \\
\text { EPI }\end{array}$ & $\begin{array}{l}\text { Verificar se os agrotóxicos estão } \\
\text { dentro do limite de isenção } \\
\text { para transporte (dependente da } \\
\text { classificação toxicológica) }\end{array}$ & $\begin{array}{l}\text { Construção com boa ventilação e } \\
\text { iluminação natural. Não permitir entrada } \\
\text { de animais }\end{array}$ \\
\hline $\begin{array}{l}\text { Conferir prazo de validade } \\
\text { dos agrotóxicos }\end{array}$ & $\begin{array}{l}\text { Se a quantidade estiver dentro do } \\
\text { limite de isenção, usar veículo com } \\
\text { caçamba externa (caminhonete, } \\
\text { caminhão, etc.) }\end{array}$ & $\begin{array}{l}\text { As instalações elétricas devem estar em } \\
\text { boas condições para evitar curto-circuito } \\
\text { e incêndios }\end{array}$ \\
\hline $\begin{array}{l}\text { Verificar se existem danos } \\
\text { e/ou vazamentos na } \\
\text { embalagem }\end{array}$ & $\begin{array}{l}\text { Se quantidade acima do limite } \\
\text { de isenção, solicitar entrega por } \\
\text { motorista e veículo preparados } \\
\text { segundo RTTP }\end{array}$ & $\begin{array}{l}\text { Portas devem permanecer trancadas para } \\
\text { evitar entrada de crianças e pessoas não } \\
\text { autorizadas }\end{array}$ \\
\hline $\begin{array}{l}\text { Verificar se informações de } \\
\text { rótulo e bula estão legíveis }\end{array}$ & $\begin{array}{l}\text { Não transportar dentro da cabine } \\
\text { e nunca transportar embalagens } \\
\text { danificadas e/ou com vazamentos }\end{array}$ & $\begin{array}{l}\text { Embalagens devem ser colocadas em } \\
\text { prateleiras de metal ou sobre estrados, } \\
\text { sem contato com o piso, paredes e teto }\end{array}$ \\
\hline
\end{tabular}


Quadro 1. continuação

\begin{tabular}{|c|c|c|}
\hline Aquisição & Transporte & Armazenamento \\
\hline $\begin{array}{l}\text { Perguntar sobre como usar } \\
\text { os EPI }\end{array}$ & $\begin{array}{l}\text { Não transportar na carroceria junto } \\
\text { com pessoas, animais, alimentos, } \\
\text { rações ou medicamentos }\end{array}$ & $\begin{array}{l}\text { Não armazenar junto com alimentos, } \\
\text { rações, sementes, medicamentos e } \\
\text { produtos inflamáveis }\end{array}$ \\
\hline \multirow[t]{3}{*}{$\begin{array}{l}\text { Certificar se o comerciante } \\
\text { forneceu informação sobre } \\
\text { local de devolução de } \\
\text { embalagens vazias }\end{array}$} & $\begin{array}{l}\text { Usar cofre de carga para } \\
\text { acondicionar os agrotóxicos em caso } \\
\text { de transporte com outro tipo de } \\
\text { produto }\end{array}$ & $\begin{array}{l}\text { Não fazer estoques além das quantidades } \\
\text { para uso em curto prazo }\end{array}$ \\
\hline & $\begin{array}{l}\text { Cobrir as embalagens com lona } \\
\text { impermeável, presa à carroceria }\end{array}$ & $\begin{array}{l}\text { Os agrotóxicos devem ser mantidos nas } \\
\text { embalagens originais e fechadas }\end{array}$ \\
\hline & $\begin{array}{l}\text { Em caso de acidente providenciar } \\
\text { recolhimento das porções vazadas. } \\
\text { EPI devem estar disponíveis no } \\
\text { veículo }\end{array}$ & $\begin{array}{l}\text { O rótulo deve sempre permanecer visível } \\
\text { e legível e as embalagens separadas por } \\
\text { tipo (herbicidas, inseticidas, etc.) }\end{array}$ \\
\hline Preparo e aplicação & Destino final embalagens vazias & Lavagem roupas/EPIs contaminados \\
\hline $\begin{array}{l}\text { O manuseio deve ser } \\
\text { feito por pessoas adultas } \\
\text { (entre } 18 \text { e } 60 \text { anos) e bem } \\
\text { informadas sobre os riscos } \\
\text { (com treinamento de no } \\
\text { mínimo } 20 \text { horas) }\end{array}$ & $\begin{array}{l}\text { Devolver todas as embalagens } \\
\text { vazias dos agrotóxicos na unidade } \\
\text { de recebimento indicada pelo } \\
\text { comerciante na nota fiscal }\end{array}$ & $\begin{array}{l}\text { Usar luvas de Nitrila ou Neoprene e } \\
\text { avental impermeável }\end{array}$ \\
\hline $\begin{array}{l}\text { Ler nos rótulos e bulas } \\
\text { as informações sobre } \\
\text { manuseio, precauções, } \\
\text { primeiros socorros, } \\
\text { destinação de embalagens } \\
\text { vazias, equipamentos de } \\
\text { proteção, etc. }\end{array}$ & $\begin{array}{l}\text { Realizar tríplice lavagem, lavagem } \\
\text { sob pressão ou acondicionamento de } \\
\text { embalagens não laváveis, seguindo } \\
\text { os procedimentos específicos de } \\
\text { cada atividade }\end{array}$ & $\begin{array}{l}\text { Lavar as roupas/EPI usados no preparo } \\
\text { e aplicação separados das demais roupas } \\
\text { da família e em tanque exclusivo para a } \\
\text { atividade }\end{array}$ \\
\hline $\begin{array}{l}\text { Utilizar EPI para proteger a } \\
\text { saúde, reduzindo os riscos } \\
\text { de intoxicação }\end{array}$ & $\begin{array}{l}\text { Inutilizar as embalagens (perfurar } \\
\text { o fundo) para armazenamento pré- } \\
\text { devolução e para devolução }\end{array}$ & $\begin{array}{l}\text { Enxaguar com bastante água corrente } \\
\text { para diluir e remover os resíduos de } \\
\text { agrotóxico }\end{array}$ \\
\hline $\begin{array}{l}\text { Os EPI necessários são: } \\
\text { calça, jaleco, botas, avental, } \\
\text { respirador (máscara), } \\
\text { viseira, luvas, boné árabe. } \\
\text { Cada um deve seguir } \\
\text { disposições específicas }\end{array}$ & $\begin{array}{l}\text { Devolver as embalagens em até um } \\
\text { ano e meio após a compra }\end{array}$ & Usar sabão neutro e não deixar de molho \\
\hline $\begin{array}{l}\text { Lavar as luvas ainda } \\
\text { vestidas e seguir uma } \\
\text { sequência lógica para } \\
\text { retirar os EPI (boné, viseira, } \\
\text { avental, jaleco, botas, calça, } \\
\text { luvas, respirador) }\end{array}$ & $\begin{array}{l}\text { Apresentar nota fiscal de compra } \\
\text { de cada produto no momento da } \\
\text { devolução }\end{array}$ & $\begin{array}{l}\text { Não usar alvejante nem esfregar as } \\
\text { roupas hidrorrepelentes }\end{array}$ \\
\hline $\begin{array}{l}\text { Preparar ao ar livre e longe } \\
\text { de crianças, animais e } \\
\text { pessoas desprotegidas. }\end{array}$ & & $\begin{array}{l}\text { Passar as roupas hidrorrepelentes para } \\
\text { prolongar a vida útil }\end{array}$ \\
\hline
\end{tabular}


Quadro 1. continuação

\begin{tabular}{|c|c|c|}
\hline Preparo e aplicação & $\begin{array}{l}\text { Destino final } \\
\text { embalagens vazias }\end{array}$ & Lavagem roupas/EPIs contaminados \\
\hline $\begin{array}{l}\text { Usar água limpa para evitar entupimento dos } \\
\text { bicos do pulverizador }\end{array}$ & & Não colocar os EPI para secar ao sol \\
\hline $\begin{array}{l}\text { Utilizar balanças, copos graduados, baldes e } \\
\text { funis específicos para preparar a calda. Lavar os } \\
\text { utensílios ao término do preparo e secar ao sol }\end{array}$ & & $\begin{array}{l}\text { Após lavadas e secas, guardar as } \\
\text { roupas/EPI utilizados no preparo } \\
\text { e aplicação separados das demais } \\
\text { roupas da família }\end{array}$ \\
\hline $\begin{array}{l}\text { Ler manual de instruções do equipamento de } \\
\text { aplicação e calibrar corretamente }\end{array}$ & & $\begin{array}{l}\text { O esgotamento da água de lavagem } \\
\text { deve ser feito direto para fossa séptica } \\
\text { para tratamento de resíduos químicos }\end{array}$ \\
\hline \multicolumn{3}{|l|}{$\begin{array}{l}\text { Não utilizar equipamentos de aplicação com } \\
\text { defeitos ou vazamentos }\end{array}$} \\
\hline \multicolumn{3}{|l|}{$\begin{array}{l}\text { Verificar velocidade do vento e temperatura } \\
\text { antes de aplicar (dar preferência para horários } \\
\text { menos quentes do dia) }\end{array}$} \\
\hline \multicolumn{3}{|l|}{$\begin{array}{l}\text { Não desentupir bicos com a boca, não beber, } \\
\text { comer ou fumar durante aplicação. Lavar mãos } \\
\text { e rosto antes de comer, beber ou fumar }\end{array}$} \\
\hline \multicolumn{3}{|l|}{$\begin{array}{l}\text { Manter barba e unhas feitas. Tomar banho assim } \\
\text { que terminar aplicação e colocar roupas limpas }\end{array}$} \\
\hline $\begin{array}{l}\text { Respeitar período de reentrada (tempo em } \\
\text { que ninguém deve entrar sem EPI nas áreas } \\
\text { tratadas) e o intervalo de segurança (tempo que } \\
\text { deve ser respeitado entre aplicação e colheita) }\end{array}$ & & \\
\hline
\end{tabular}

atividades de trabalho citadas para que o uso de agrotóxicos não seja considerado “inadequado" e traga proteção à saúde dos trabalhadores rurais.

No entanto, estudos realizados no Brasil têm mostrado que o contexto atual de utilização intensiva e indiscriminada de agrotóxicos, associado ao paradigma de proteção de trabalhadores rurais através do "uso seguro", não traz perspectivas de redução dos casos intoxicações agudas ${ }^{30-46}$ e dos agravos à saúde decorrentes da exposição de longo prazo ${ }^{47-51}$.

Este artigo apresenta uma revisão crítica sobre o "uso seguro" de agrotóxicos em artigos científicos brasileiros. O objetivo é identificar nesses trabalhos a abordagem de cada uma das seis atividades de trabalho que apresentam risco potencial de intoxicação de trabalhadores rurais e a abrangência com que as diversas medidas de segurança, descritas como determinantes para a manipulação "correta” e com "controle dos riscos" dos agrotóxicos, são abordadas em cada uma dessas atividades.

\section{Métodos}

Artigos científicos publicados entre os anos 2000 e 2014, com investigação baseada em dados empíricos coletados no Brasil, foram procurados. Esta abrangência temporal foi definida devido à concentração de pesquisas relacionadas ao uso e às intoxicações por agrotóxicos no País a partir do ano 2000. Acredita-se que após dez anos de vigência da Lei dos Agrotóxicos ${ }^{13}$ e do exponencial crescimento do consumo desses produtos no Brasil, ficou evidente a necessidade de investigar 
as consequências do uso intensivo de agroquímicos e a eficácia da legislação no que diz respeito à proteção da saúde dos trabalhadores rurais.

As buscas, realizadas em dezembro de 2012, novembro de 2013 e maio de 2014, incluíram o banco de dados SCIELO, utilizando-se os descritores: agrotóxicos AND saúde; praguicidas AND saúde; pesticidas AND saúde. Optou-se por esta busca ampla após perceber-se a diversidade de palavras utilizadas nos manuais de "uso seguro" de agrotóxicos para se referir às atividades de aquisição, transporte, armazenamento, preparo e aplicação, destino final de embalagens vazias e lavagem de roupas/ EPI contaminados e aos aspectos referentes a cada uma destas atividades. Além disso, entendeu-se que todo trabalho que aborde as medidas de "uso seguro" nestas seis atividades, e as relacione com aspectos de saúde de trabalhadores rurais, estaria dentro da abrangência desta busca.

Todos os artigos encontrados tiveram seus títulos e resumos lidos para identificação e seleção de trabalhos que pudessem apresentar algum tipo de abordagem sobre o "uso seguro" de agrotóxicos.

Nos trabalhos selecionados, utilizou-se a ferramenta de localização de palavras do software de leitura de arquivos em formato PDF para identificar, em toda a extensão textual dos artigos, palavras relacionadas às especificidades das seis atividades de trabalho. Para a atividade de aquisição, foram utilizadas as palavras "aquisição", "compra", "venda", "receituário agronômico", "receita" e "nota fiscal"; para a atividade de transporte, utilizou-se as palavras "transporte", "caminhonete", "caçamba", "carroceria", "carro", "cabine", "trânsito" e "multa"; para identificar artigos com abordagem sobre a atividade de armazenamento, buscou-se as palavras "armazenamento", "acondicionamento", "armazenar", "acondicionar", "guardar", "estocar", "estoque”, "construção", "estrutura", "prateleira", "estrado" e "embalagem"; para a atividade de preparo e aplicação, foram utilizadas as palavras "preparo", "preparar", "mistura", "calda", "aplicação", "pulverização", "aplicador", "bomba”, "manuseio", "manipulação", "rótulo", "bula”, "EPI", “equipamento", "proteção", "período de carência", "período de reentrada", "intervalo de segurança" e "higiene pessoal"; a atividade de destino final de embalagens vazias foi identificada através das palavras "devolução", "descarte", "destino", "lixo", "coleta", "entrega", "embalagem", "embalagens", "vasilhame”, "vazia", "tríplice lavagem", "queima", "reaproveitar", "inutilizar" e "perfurar"; e para a atividade de lavagem de roupas/ EPI contaminados foram utilizadas as palavras "lavar", "lavagem", "roupas", "EPI", "equipamentos" e "tanque".

Após a leitura completa dos trabalhos selecionados na etapa anterior, foram excluídos os debates, artigos de revisão, ensaios, artigos originais com análise de dados secundários e também artigos originais que citavam, em sua fundamentação teórica, atividades de trabalho e medidas de segurança de interesse para esta revisão, porém, não traziam resultados e/ou análises de dados coletados sobre as mesmas. Permaneceram, portanto, apenas estudos empíricos de campo que buscavam investigar as implicações da manipulação de agrotóxicos à saúde de trabalhadores rurais.

É importante ressaltar que não foram consideradas como critérios para a seleção dos artigos a metodologia utilizada (se quantitativa ou qualitativa) nem a qualidade científica dos resultados e discussões apresentados nos trabalhos, mas sim, se apresentavam conteúdo sobre o "uso seguro" de agrotóxicos. Por fim, não necessariamente o "uso seguro" deveria ser o tópico primário destes trabalhos, mas sim, deveriam apresentar algum tipo de abordagem de atividade(s) de trabalho que envolva $(\mathrm{m})$ risco e/ou medida(s) de segurança que faça $(\mathrm{m})$ parte do escopo do paradigma do "uso seguro" de agrotóxicos.

\section{Resultados}

Foi encontrado um total de 114 artigos contendo as palavras "agrotóxicos", ou "praguicidas", ou "pesticidas" e "Saúde". A leitura dos títulos e resumos dos 114 artigos permitiu a seleção de 60 que sugeriam algum tipo de abordagem sobre o "uso seguro" de agrotóxicos. Destes, 41 artigos contendo palavras relacionadas às especificidades das seis atividades de trabalho em estudo foram identificados e selecionados. Após a leitura completa dos mesmos, chegou-se à seleção final de 25 artigos que abordam práticas de trabalho e medidas de segurança relacionadas aos agrotóxicos nas atividades de aquisição, transporte, armazenamento, preparo e aplicação, destino final de embalagens vazias e lavagem de roupas/EPI contaminados, apresentando e analisando dados coletados em diversas e distintas regiões e comunidades rurais brasileiras.

\section{Abordagem do "uso seguro" nas atividades de trabalho com agrotóxicos}

Através da revisão dos artigos da seleção final, foram encontrados 10 estudos apresentado 
dados referentes às medidas de "uso seguro" na atividade de aquisição de agrotóxicos; apenas um abordando práticas relacionadas ao transporte; seis apresentavam abordagem sobre práticas de armazenamento; 25 trazendo resultados e/ou análises sobre práticas relacionadas às medidas de segurança no preparo e aplicação de agrotó- xicos; 17 abordando práticas de segurança relacionadas ao destino final de embalagens vazias; e nove com dados referentes às práticas de lavagem de roupas/ EPI contaminados. As atividades abordadas em cada artigo, o local de realização da coleta de dados, assim como os autores e o ano de publicação, estão descritos no Quadro 2.

Quadro 2. Estudos segundo abordagem das atividades de trabalho com agrotóxicos. Brasil, 2000-2014.

\begin{tabular}{|c|c|c|c|c|c|c|c|}
\hline Estudo & Local do estudo & AQ & TR & AR & $\mathrm{PeA}$ & DFE & LRC \\
\hline $\begin{array}{l}\text { Araújo ACP, Nogueira DP, Augusto LGS, } \\
2000^{52}\end{array}$ & $\begin{array}{l}\text { Camocim de São Félix e perímetro irrigado } \\
\text { do Vale do São Francisco (PE) }\end{array}$ & $\mathrm{X}$ & & & $\mathrm{X}$ & $\mathrm{X}$ & $\mathrm{X}$ \\
\hline Faria NMX et al., $2000^{30}$ & Antônio Prado e Ipê (RS) & & & & $\mathrm{X}$ & $\mathrm{X}$ & $\mathrm{X}$ \\
\hline Oliveira-Silva et al., $2001^{31}$ & Magé (RJ) & & & & $\mathrm{X}$ & & \\
\hline Moreira JC et al., $2002^{53}$ & Nova Friburgo (RJ) & & & & $\mathrm{X}$ & & \\
\hline Soares W, Almeida RM, Moro S, $2003^{32}$ & $\begin{array}{l}\text { Teófilo Otoni, Gudoval, Guiricema, Montes } \\
\text { Claros, Paracatu, Piraúba, Tocantins, Ubá, } \\
\text { Uberlândia (MG) }\end{array}$ & $\mathrm{X}$ & & & $\mathrm{X}$ & & \\
\hline Delgado IF, Paumgartten FJR, $2004^{54}$ & Paty do Alferes (RJ) & $\mathrm{X}$ & & $\mathrm{X}$ & $\mathrm{X}$ & $\mathrm{X}$ & $\mathrm{X}$ \\
\hline Faria NMX et al., $2004^{33}$ & Antônio Prado e Ipê (RS) & & & & $\mathrm{X}$ & & $\mathrm{X}$ \\
\hline Gomide $\mathrm{M}, 2005^{55}$ & São João da Costa e São João do Piauí (PI) & & & $\mathrm{X}$ & $\mathrm{X}$ & $\mathrm{X}$ & \\
\hline Castro JSM, Confalonieri U, $2005^{34}$ & Cachoeiras de Macacu (RJ) & $\mathrm{X}$ & & $\mathrm{X}$ & $\mathrm{X}$ & $\mathrm{X}$ & $\mathrm{X}$ \\
\hline $\begin{array}{l}\text { Soares WL, Freitas EAV, Coutinho JAG, } \\
2005^{35}\end{array}$ & Teresópolis (RJ) & $\mathrm{X}$ & & & $\mathrm{X}$ & $\mathrm{X}$ & \\
\hline Shmidt MLG, Godinho PH, $2006^{36}$ & Interior do Estado de SP (SP) & & $\mathrm{X}$ & & $\mathrm{X}$ & $\mathrm{X}$ & \\
\hline Fonseca MGU et al., $2007^{56}$ & Barbacena (MG) & & & & $\mathrm{X}$ & $\mathrm{X}$ & \\
\hline Araújo AJ et al., $2007^{57}$ & Nova Friburgo (RJ) & & & & $\mathrm{X}$ & & \\
\hline Recena MCP, Caldas ED, $2008^{58}$ & Culturama (MS) & $\mathrm{X}$ & & & $\mathrm{X}$ & $\mathrm{X}$ & \\
\hline Brito PF, Gomide M, Câmara VM, $2009^{39}$ & $\begin{array}{l}\text { Serrinha do Mendanha, município do Rio } \\
\text { de Janeiro (RJ) }\end{array}$ & & & $\mathrm{X}$ & $\mathrm{X}$ & $\mathrm{X}$ & $\mathrm{X}$ \\
\hline $\begin{array}{l}\text { Alves SMF, Fernandes PM, } \\
\text { Reis EF, } 2009^{42}\end{array}$ & $\begin{array}{l}\text { Bonfinópolis, Corumbá de Goiás, } \\
\text { Goianópolis, Leopoldo de Bulhões, } \\
\text { Pirenópolis e Silvânia (GO) }\end{array}$ & & & & $\mathrm{X}$ & & \\
\hline Jacobson LSV et al., $2009^{5}$ & Santa Maria de Jetibá (ES) & & & & $\mathrm{X}$ & $\mathrm{X}$ & $\mathrm{X}$ \\
\hline Bedor CNG et al., 200941 & Petrolina (PE) e Juazeiro (BA) & $\mathrm{X}$ & & & $\mathrm{X}$ & $\mathrm{X}$ & \\
\hline $\begin{array}{l}\text { Faria NMX, Rosa JAR, Facchini LA, } \\
2009^{40}\end{array}$ & Bento Gonçalves (RS) & $\mathrm{X}$ & & & $\mathrm{X}$ & $\mathrm{X}$ & \\
\hline $\begin{array}{l}\text { Marques CRG, Neves PMOJ, Ventura } \\
\text { MU, } 2010^{43}\end{array}$ & Londrina $(\mathrm{PR})$ & & & $\mathrm{X}$ & $\mathrm{X}$ & $\mathrm{X}$ & \\
\hline Gregolis TBL, Pinto WJ, Peres F, $2012^{59}$ & Rio Branco (AC) & & & & $\mathrm{X}$ & & $\mathrm{X}$ \\
\hline Júnior EEF et al., $2012^{60}$ & Ponta Porã (MS) & & & & $\mathrm{X}$ & & $\mathrm{X}$ \\
\hline Gonçalves GMS et al., $2012^{46}$ & Pesqueira (PE) & $\mathrm{X}$ & & & $\mathrm{X}$ & $\mathrm{X}$ & \\
\hline Preza DLC, Augusto LGS, $2012^{44}$ & Conceição do Jacuípe (BA) & & & $\mathrm{X}$ & $\mathrm{X}$ & $\mathrm{X}$ & \\
\hline Silva JPL, Araújo MZ, Melo LCQ, 2013 ${ }^{61}$ & São José de Princesa (PB) & $\mathrm{X}$ & & & $\mathrm{X}$ & $\mathrm{X}$ & \\
\hline
\end{tabular}

${ }^{\text {a }}$ Legenda: AQ - Aquisição; TR - Transporte; AR - Armazenamento; PeA - Preparo e Aplicação; DFE - Destino final de embalagens vazias; LRC Lavagem de roupas/EPIs contaminados. 


\section{Abrangência da abordagem do "uso seguro" de agrotóxicos nas atividades}

\section{Aquisição}

A leitura detalhada dos 10 artigos, que descrevem práticas de agricultores na atividade de compra dos agrotóxicos, revela que a abordagem desses trabalhos se resume a três medidas: conhecimento e uso da receita agronômi$\mathrm{ca}^{32,34,35,40,41,46,52}$, orientação técnica no momento da compra ${ }^{32,40,52,58,61}$ e responsável pela indicação do agrotóxico a ser comprado ${ }^{34,41,54}$.

Com relação ao uso da receita agronômica, Araújo et al..$^{52}$ apontam que apenas $36,0 \%$ dos agricultores entrevistados afirmaram precisar deste instrumento para adquirir os agrotóxicos, sendo que 30,0\% dos trabalhadores sequer o conheciam. Bedor et al. ${ }^{41}$, Gonçalves et al. ${ }^{46}$, Soares et al. ${ }^{32}$, Castro e Confalonieri ${ }^{34}$ e Soares et al. ${ }^{35}$ descrevem o não uso da receita agronômica por, respectivamente, $64,7 \%, 67,2 \%, 83,3 \%$, $85,0 \%$ e $88,9 \%$ dos entrevistados. Apenas Faria et al. ${ }^{40}$ apontam que a maioria dos entrevistados $(84,6 \%)$ recebem a cópia da receita no momento da compra. No entanto, o mesmo trabalho indica que $73,0 \%$ dos entrevistados recebem orientação técnica de vendedores ou técnicos da cooperativa.

Essa orientação com conflito de interesse, que inviabiliza o aspecto de segurança da receita agronômica, é também recebida por $74,1 \%$ dos agricultores entrevistados no trabalho de Recena e Caldas ${ }^{58}$. Estes, assim como Silva et al. ${ }^{61}$, trazem falas transcritas de agricultores evidenciando que tais orientações se restringem à dosagem do agrotóxico a ser preparado e aplicado. Os comércios responsáveis pela venda dos agrotóxicos são incipientes quanto à orientação [...]. Falta orientação quanto ao descarte e aos riscos que essas pessoas estão sujeitas... ${ }^{61}$, ressaltam os autores. Soares et al. ${ }^{32}$ ainda apontam, através de inferência estatística, que os trabalhadores que recebem orientação do vendedor na compra e no uso de agrotóxicos têm $73 \%$ a mais de chance de se intoxicar em relação àqueles que não têm o vendedor como orientador ${ }^{32}$.

Por fim, Faria et al. ${ }^{40}$, Delgado e Paumgart$\operatorname{ten}^{54}$ e Castro e Confalonieri ${ }^{34}$ revelam que familiares, vizinhos e amigos agricultores, sócios e donos das terras onde trabalham os agricultores entrevistados exercem papel mais importante na indicação do agrotóxico a ser adquirido, do que técnicos da Empresa de Assistência Técnica e Extensão Rural (Emater), ou Engenheiros Agrônomos que não são funcionários de estabelecimentos comerciais.

\section{Transporte}

A atividade de transporte de agrotóxicos por agricultores, apesar de oferecer riscos a estes trabalhadores, a outros motoristas e passageiros é a atividade que apresenta maior carência em relação a estudos que abordam medidas de "uso seguro" na utilização destes produtos.

No único trabalho encontrado que faz alusão ao transporte de agrotóxicos, Shmidt e Godinho ${ }^{36}$ afirmam que a maioria dos entrevistados toma os cuidados necessários durante o transporte de tais produtos $^{36}$, porém, não especificam quais das diversas medidas obrigatórias para que a atividade possa ser considerada segura são realizadas. Em seguida, ao apresentarem falas de agricultores, que evidenciam o transporte de agrotóxicos juntamente com outros produtos, e também a preocupação dos trabalhadores rurais com a fiscalização de trânsito e não com a proteção da própria saúde, os autores afirmam que alguns discursos denunciam o descaso dos entrevistados ${ }^{36}$.

Entende-se que o emprego da palavra "descaso", desvinculada de qualquer análise sobre a viabilidade econômica e prática de se realizar mais de uma viagem aos centros urbanos, para transportar separadamente agrotóxicos e demais produtos, e sobre a inexistência de políticas públicas que responsabilizem indústrias químicas e estabelecimentos comerciais pelos riscos e acidentes de trânsito envolvendo agrotóxicos, acaba por corroborar a culpabilização do agricultor e, consequentemente, as intenções das indústrias químicas com a implantação do paradigma do "uso seguro" de agrotóxicos.

\section{Armazenamento}

O local de armazenamento dos agrotóxicos (construção independente da residência, ar livre ou dentro de casa $)^{34,39,43,44,55}$ e se este local permanece trancado ${ }^{43,54}$ são as únicas medidas abordadas pelos seis artigos que trazem resultados sobre essa atividade.

Sem apresentar a frequência de agricultores que armazenavam agrotóxicos em local considerado inseguro, Gomide ${ }^{55}$ verificou que estes podiam estar 'escondidos' entre os ramos dos vegetais, em galhos de árvores ou em varandas, interior ou anexos de suas residências" ${ }^{\prime \prime 5}$. Os demais artigos que abordam o local de armazenamento trazem frequências que variam de $1,7 \%$ a $24,0 \%$ de agricultores que afirmaram deixar os agrotóxicos ao ar livre ou guardar dentro da própria residência, práticas que envolvem risco de contaminação, por substâncias tóxicas concentradas, dos ambientes habitados e frequentados cotidianamente pela família. 
Por outro lado, apesar dos mesmos estudos indicarem elevadas frequências (70,0\% a 98,3\%) de armazenamento em construções independentes da residência, como determina o paradigma do "uso seguro", nenhum destes artigos traz informações sobre as condições estruturais destes depósitos. Para afirmar que o armazenamento nestes locais é seguro, seria necessário avaliar materiais utilizados na construção, conservação de pisos, paredes, telhados e fiações elétricas, distância do local até residências e fontes de água, forma de acondicionamento dentro destes locais e aspectos como existência de placas de advertência e de controle de acesso aos agrotóxicos. Apenas quanto a esta última medida, Delgado e Paumgartten ${ }^{54}$ e Marques et al. ${ }^{43}$ indicam que $52,0 \%$ e $98,3 \%$ dos agricultores, respectivamente, guardam os agrotóxicos em local trancado.

\section{Preparo e Aplicação}

A atividade de preparo e aplicação de agrotóxicos apresenta a maior abrangência no que diz respeito à abordagem das medidas de "uso seguro" nos artigos analisados. Todos os 25 trabalhos apresentam resultados relacionados com esta atividade. As medidas de segurança abordadas são leitura de rótulo e bula ${ }^{31,32,36,41,43,46,57,58}$, modo de uso e falta de assistência técnica ${ }^{31,34,35,44,53,54,57}$, período de carência ${ }^{32,35,39,44,52}$, higiene pesso$\mathrm{al}^{34,39,54,56,57}$, aspectos relacionados aos equipamentos de aplicação ${ }^{34,35,40,41,46}$, intervalo de segurançç ${ }^{30}$, verificação das condições climáticas antes da aplicação ${ }^{52}$ e proximidade entre área de aplicação e a residência da família ${ }^{58}$.

No entanto, é importante ressaltar que apenas aspectos relacionados aos Equipamentos de Proteção Individual, como a utilização, quais os componentes utilizados, ineficácia dos mesmos, razões para o não uso, contato dos agrotóxicos com o corpo, etc., apresentam resultados e/ou análises em todos os estudos. Entre abordagens quantitativas e qualitativas, a grande maioria dos artigos indica a baixa adesão dos agricultores aos $\mathrm{EPI}^{5,34-36,39,42,44,46,52-54,56-61}$, sendo os principais motivos analisados o desconforto causado pelos mesmos ${ }^{5,34,35,39,42,43,54,56,58-61}$, a falta de recursos financeiros para adquiri-los ${ }^{5,36,39,46,54,55}$, e questões culturais $^{39,42,54,61}$.

Quanto a ineficácia dos EPI, trabalho de Brito et al..$^{39}$ afirma que é esperado que o uso de EPI possa minimizar a ocorrência de episódios de intoxicação, mas os extensos danos crônicos que o agrotóxico traz ao ambiente, à biodiversidade e ao próprio homem devem ser trabalhados através de uma mudança de paradigma na agricultura, que reduza e até mesmo um dia venha a excluir o uso destes quimicos $^{39}$. Já o trabalho de Faria et al..$^{40}$ aponta que, apesar da grande adesão e da maior proporção de casos de intoxicação entre os que não usam EPI, ocorreram vários casos de intoxicação entre trabalhadores que sempre usavam essas medidas de proteçã $0^{40}$ (mais de 92,0\% dos casos prováveis de intoxicação informaram usar sempre todos EPI), o que, segundo a análise dos autores, indica que fontes de exposição ambiental e alimentar, ou seja, não ocupacionais, e a não utilização dos EPI em atividades laborais que exigem a reentrada nas áreas recém pulverizadas, podem ter influenciado os resultados de intoxicação encontrados. No entanto, considerando-se o objeto de estudo desta revisão, acredita-se que estes casos de intoxicação podem também ter ocorrido nas demais práticas laborais que não as relacionadas diretamente com a atividade de preparo e aplicação de agrotóxicos.

\section{Destino final de embalagens vazias}

Dentre os 17 artigos que abordam o destino dado às embalagens vazias de agrotóxicos, dois estudos trazem resultados sobre a forma/ local de descarte e sobre a realização da tríplice lavagem nas embalagens antes do descarte ${ }^{46,55}$. Gonçalves et al. ${ }^{46}$ revelam que apenas 5,4\% dos agricultores entrevistados realizam esta técnica de lavagem e Gomide $^{55}$ descreve que a tríplice lavagem não é realizada (nas localidades onde o estudo foi conduzido) tanto por desconhecimento como por falta de água para este fim $\mathrm{m}^{55}$.

Os outros 15 trabalhos apontam apenas a for$\mathrm{ma} /$ local de descarte das embalagens, sendo que Fonseca et al. ${ }^{56}$ apenas citam que este é o único comportamento adequado em relação às normas de proteção. Soares et al. ${ }^{35}$ indicam que o recolhimento das embalagens pelo sistema de coleta de lixo é um fator de proteção identificado por sua pesquisa e Gomide ${ }^{55}$ lista variações da forma incorreta de descarte, porém, sem apresentar a frequência da realização destas pelos agricultores.

Brito et al. ${ }^{39}$, Araújo et al..$^{52}$, Silva et al. ${ }^{61}$, Recena e Caldas ${ }^{58}$, Faria et al..$^{30}$, Castro e Confalonieri $^{34}$, Delgado e Paumgartten ${ }^{54}$ e Gonçalves et al. ${ }^{46}$ indicam que a quantidade de agricultores entrevistados que joga as embalagens vazias no mato, deixa na área de cultivo, queima, enterra, reaproveita para uso doméstico e/ou joga em lixo comum é maior que a quantidade de agricultores que entrega as embalagens no estabelecimento onde foi realizada a compra ou em postos de coleta destes vasilhames. Gonçalves et al. ${ }^{46}$ analisam que os entrevistados são orientados pelos vendedores a realizar a devolução em um posto 
de recolhimento distante da comunidade, o que, segundo os autores, é oneroso e corrobora para o descarte de embalagens no ambiente ${ }^{46}$.

Bedor et al. ${ }^{41}$, Jacobson et al. ${ }^{5}$, Faria et al. ${ }^{40}$, Shmidt e Godinho ${ }^{36}$, Preza e Augusto ${ }^{44}$ e Marques et al. ${ }^{43}$ apontam uma quantidade maior de agricultores que descartam as embalagens vazias seguindo os procedimentos recomendados nos manuais de segurança. Apesar dos resultados aparentemente positivos, Bedor et al..$^{41}$ aponta mque a associação do comércio agropecuário, onde $78,0 \%$ dos entrevistados disseram entregar as embalagens, há cerca de um ano não realiza a coleta, o que justifica a observação de várias embalagens de agrotóxicos jogadas no meio do mato ${ }^{41} \mathrm{e}$ Marques et al. ${ }^{43}$ revelam que muitos entrevistados relataram a longa distância da propriedade até o ponto de devolução, o que gera despesas, motivo que não incentiva a devolução da embalagem ${ }^{43}$. Já Shmidt e Godinho $^{36}$ não analisam os aspectos que dificultam o cumprimento desta medida por parte dos agricultores e afirmam que, apesar da cooperativa disponibilizar postos próprios e conveniados apropriados para o recebimento das embalagens tríplice-lavadas [...] há alguns discursos que denunciam o descaso em relação ao procedimento, o que denota falta de conscientização de alguns sobre o problema da contaminação ambiental em decorrência do descarte inapropriado ${ }^{36}$, transferindo a responsabilidade das indústrias químicas, comércios e governos para os agricultores.

\section{Lavagem de roupas/EPI contaminados}

$\mathrm{Na}$ última atividade, onde medidas de segurança são determinantes para a proteção da saúde dos trabalhadores rurais, segundo o paradigma do "uso seguro" de agrotóxicos, a análise dos nove artigos, que trazem resultados sobre a lavagem de roupas/ EPI contaminados, revelou que, a prevalência de mulheres na realização desta atividade ${ }^{30,33,59,60}$, o local de realização da ativida$\mathrm{de}^{34,35,52} \mathrm{e}$ a separação das peças contaminadas das demais roupas da família no momento da lavagem $^{54,60}$, foram os únicos aspectos abordados por estes trabalhos. Fonseca et al. ${ }^{56}$ apenas citam que, quanto à lavagem da roupa (contaminada), seria esperado que fosse adotado um comportamento que seguisse as normas de proteção. Entretanto, observa-se que nem sempre esses cuidados são efetivamente tomados ${ }^{56}$, sem apresentar resultados sobre quais medidas não eram seguidas e sobre quais eram os comportamentos esperados.

Com relação ao local de realização da atividade, Araújo et al. ${ }^{52}$ e Castro e Confalonieri ${ }^{34}$ apontam a predominância da utilização do am- biente (tanque) doméstico, enquanto Soares et al. ${ }^{35}$ revelam, por meio de inferência estatística, que lavar os equipamentos em tanque de uso doméstico aumenta as chances de intoxicação em $350 \%{ }^{35}$. Júnior et al. ${ }^{60}$ e Delgado e Paumgartten ${ }^{54}$ apontam que a lavagem separada das roupas/ EPI contaminados das demais roupas da família não é realizada com a intenção de evitar contaminação destas, mas por considerarem essas "roupas de trabalho" mais sujas e mau cheirosas (odor dos agrotóxicos).

Por fim, Faria et al..$^{30}$, Faria et al. ${ }^{33}$, Gregolis et al. ${ }^{59}$ e Júnior et al. ${ }^{60}$ apontam que mulheres são majoritariamente responsáveis pela realização desta atividade, sendo que os dois últimos trabalhos apontam, respectivamente, uma possivel invisibilidade dos riscos enfrentados pelas mulheres na realização desta atividade ${ }^{59}$ e a exposição somatória vivenciada pelas mulheres (através de exposição indireta mais a lavagem e higiene das roupas) [...] que gera possibilidade de transferência de resíduos de agrotóxicos dessas mulheres para fetos e para crianças por meio do leite matern $0^{60}$.

\section{Conclusão}

Através da revisão dos artigos que abordam medidas de segurança nas atividades de aquisição, transporte, armazenamento, preparo e aplicação, destino final de embalagens vazias e lavagem de roupas/ EPI contaminados, onde, segundo o paradigma do "uso seguro", tais medidas são determinantes para a proteção da saúde dos agricultores e para o controle dos riscos envolvidos na utilização de agrotóxicos, observou-se que a abrangência da abordagem do "uso seguro" nestas atividades, e a própria abordagem das seis atividades de trabalho que envolvem manipulação direta das substâncias biocidas, não vêm sendo realizadas de forma ampla. Esta abordagem fragmentada e restrita pode não ser suficiente para demonstrar a completa inviabilidade da existência de "uso seguro" de agrotóxicos no contexto social, econômico, geográfico e cultural geral da agricultura brasileira e para desconstruir como um todo este pilar de sustentação para a liberação, registro, promoção e uso indiscriminado de agrotóxicos no Brasil.

\section{Colaboradores}

PHB Abreu e HGA Alonzo participaram igualmente de todas as etapas de elaboração do artigo. 


\section{Referências}

1. Associação Brasileira da Indústria Química. Brasil. A indústria química brasileira [internet]. 2013 [acessado 2014 jan 22]. Disponível em: http://www.abiquim.org. $\mathrm{br} / \mathrm{pdf} /$ indQuimica/AIndustriaQuimica-SobreSetor. pdf

2. Carneiro FF, Pignati W, Rigotto RM, Augusto LGS, Rizollo A, Muller NM, Alexandre VP, Friedrich K, Mello MSC, organizadores. Dossiê Abrasco: um alerta sobre os impactos dos agrotóxicos na saúde $1^{a}$ Parte. Rio de Janeiro: Abrasco; 2012.

3. Augusto LGS, Carneiro FF, Pignati W, Rigotto RM, Friedrich K, Faria NMX, Búrigo AC, Freitas VMT, Guiducci Filho E, organizadores. Dossiê Abrasco: um alerta sobre os impactos dos agrotóxicos na saúde $2^{a}$ Parte. Rio de Janeiro: Abrasco; 2012.

4. Rigotto RM, Carneiro FF, Marinho AMCP, Rocha MM, Ferreira MJM, Pessoa VM, Teixeira ACA, Silva MLV, Braga LQV, Teixeira MM. O verde da economia no campo: desafios à pesquisa e às políticas públicas para a promoção da saúde no avanço da modernização agrícola. Cien Saude Colet 2012; 17(6):1533-1542.

5. Jacobson LSV, Hacon SS, Alvarenga L, Goldstein RA, Gums C, Buss DF, Leda LR. Comunidade pomenara e uso de agrotóxicos: uma realidade pouco conhecida. Cien Saude Colet 2009; 14(6):2239-2249.

6. Hazel PBR, Ramasamy C. The green revolution reconsidered: the impact of high yelding rice varieties in south India. Baltimore: Johns Hopkins University Press; 1991.

7. Faria NMX. Modelo de desenvolvimento, agrotóxicos e saúde: prioridades para uma agenda de pesquisa e ação. Rev bras Saude ocup 2012; 37(125):31-39.

8. Peres F, de Lucca SR, da Ponte LMD, Rodrigues KM Rozemberg B. Percepção das condições de trabalho em uma tradicional comunidade agrícola em Boa Esperança, Nova Friburgo, Rio de Janeiro. Cad Saude Publica 2004; 20(4):1059-1068.

9. Londres F. Agrotóxicos no Brasil: um guia para ação em defesa da vida. Rio de Janeiro: AS-PTA; 2011.

10. Soares WL, Porto MF. Uso de agrotóxicos e impactos econômicos sobre a saúde. Rev Saude Publica 2012; 46(2):209-217.

11. Soares WL, Porto MF. Atividade Agrícola e externalidade ambiental: uma análise a partir do uso de agrotóxicos no cerrado brasileiro. Cien Saude Colet 2007; 12(1):131-143.

12. Porto MF, Soares WL. Modelo de desenvolvimento, agrotóxicos e saúde: um panorama da realidade agrícola brasileira e propostas para uma agenda de pesquisa inovadora. Rev bras Saude ocup 2012; 37(125):17-30.

13. Brasil. Lei no 7.802, de 11 de julho de 1989. Dispõe sobre a pesquisa, a experimentação, a produção, a embalagem e rotulagem, o transporte, o armazenamento, a comercialização, a propaganda comercial, a utilização, a importação, a exportação, o destino final dos resíduos e embalagens, o registro, a classificação, o controle, a inspeção e a fiscalização de agrotóxicos, seus componentes e afins, e dá outras providências. Diário Oficial da União 1989; 12 jul.
14. Brasil. Decreto no 4.074 , de 8 de Janeiro de 2002. Regulamenta a Lei no 7802 , de 11 de julho de 1989, que dispõe sobre a pesquisa, a experimentação, a produção, a embalagem e rotulagem, o transporte, o armazenamento, a comercialização, a propaganda comercial, a utilização, a importação, a exportação, o destino final dos resíduos e embalagens, o registro, a classificação, o controle, a inspeção e a fiscalização de agrotóxicos, seus componentes e afins, e dá outras providências. Diário Oficial da União 2002; 8 jan.

15. Brasil. Portaria no 86, de 3 de março de 2005. Norma regulamentadora de segurança e saúde no trabalho na agricultura, pecuária, e silvicultura, exploração florestal e aquicultura. Norma Regulamentadora n. 31. Diário Oficial da União 2005; 4 mar.

16. Food and Agriculture Organization of the United Nations. International Code of Conduct on Pesticide Management [internet]. 2013 [acessado $2013 \mathrm{dez} 19$ ]. Disponível em: http://www.fao.org/agriculture/crops/ thematic-sitemap/theme/pests/code/en/

17. Dinham B. FAO and pesticides: promotion or proscription? Ecologist 1991; 21(2):61-65.

18. Murray DL, Taylor PL. Claim no easy victories: evaluating the pesticide industry's global safe use campaign. W Develop 2000; 28(10):1735-1749.

19. Rigotto RM, Rosa IF. Agrotóxicos. In: Caldart RS, Pereira IB, Alentejano P, Frigotto G, organizadores. Dicionário da educação do campo. Rio de Janeiro: Expressão Popular; 2012. p. 86-94.

20. Sobreira AEG, Adissi PJ. Agrotóxicos: falsas premissas e debates. Cien Saude Colet 2003; 8(4):985-990.

21. Porto MF, Soares WL. Modelo de desenvolvimento, agrotóxicos e saúde: um panorama da realidade agrícola brasileira e propostas para uma agenda de pesquisa inovadora. Rev bras Saude ocup 2012; 37(125):17-30.

22. Miranda AC, Moreira JC, Caravalho R, Peres F. Neoliberalismo, uso de agrotóxicos e a crise da soberania alimentar no Brasil. Cien Saude Colet 2007; 12(1):7-14

23. Iwami A, Ferreira CP, Dinnouti LA, Bueno F, Araújo RM, Gonsalves T, Santiago T. Manual de uso correto e seguro de produtos fitossanitários. São Paulo: Linea Creativa; 2010.

24. Associação Nacional de Defesa Vegetal. Manual de transporte de produtos fitossanitários. Campinas: Linea Creativa; 2010.

25. Associação Nacional de Defesa Vegetal. Manual de armazenamento de produtos fitossanitários. Campinas: Linea Creativa; 2010.

26. Associação Nacional de Defesa Vegetal. Manual de uso correto de equipamentos de proteção individual. Campinas: Linea Creativa; 2003.

27. Associação Nacional de Defesa Vegetal. Manual segurança e saúde do aplicador de produtos fitossanitários. Campinas: Linea Creativa; 2006.

28. Associação Nacional de Defesa Vegetal. Boas práticas agrícolas no campo [internet]. 2012 [acessado $2013 \mathrm{mar}$ 21]. Disponível em: http://www.andef.com.br/manuais

29. Breilh J. Epidemiología crítica: ciência emancipadora e interculturalidad. Buenos Aires: Lugar Editorial; 2003.

30. Faria NMX, Facchini LA, Fassa AG, Tomasi E. Processo de produção rural e saúde na serra gaúcha: em estudo descritivo. Cad Saude Publica 2000; 16(1):115-128. 
31. Oliveira-Silva JJ, Alves SR, Meyer A, Perez F, Sarcinelli $\mathrm{PN}$, Mattos RC, Moreira JC. Influência de fatores socioeconômicos na contaminação por agrotóxicos, Brasil. Rev Saude Publica 2001; 35(2):130-135.

32. Soares WL, Almeida RM, Moro S. Trabalho rural e fatores de risco associados ao regime de uso de agrotóxicos em Minas Gerais, Brasil. Cad Saude Publica 2003; 19(4):1117-1127.

33. Faria NMX, Facchini LA, Fassa AG, Tomasi E. Trabalho rural e intoxicações por agrotóxicos. Cad Saude Publica 2004; 20(5):1298-1208.

34. Castro JSM, Confalonieri U. Uso de agrotóxicos no Município de Cachoeiras de Macacu (RJ). Cien Saude Colet 2004; 10(2):473-482.

35. Soares WL, Freitas EAV, Coutinho JAG. Trabalho rural e saúde: intoxicação por agrotóxicos no município de Teresópolis - RJ. Rev Econ Rural 2005; 43(4):685-701.

36. Schmidt MLG, Godinho PH. Um breve estudo acerca do cotidiano do trabalho de produtores rurais: intoxicações por agrotóxicos e subnotificação. Rev bras Saude ocup 2006; 31(113):27-40.

37. Pignatti WA, Machado JMH, Cabral JF. Acidente rural ampliado: o caso das "chuvas" de agrotóxicos sobre a cidade de Lucas do Rio Verde - MT. Cien Saude Colet 2007; 12(1):105-114.

38. Veiga MM, Duarte FJC, Meirelles LA, Garrigou A, Baldi I. A contaminação por agrotóxicos e os Equipamentos de Proteção Individual (EPI). Rev bras Saude ocup 2007; 32(116):57-68.

39. Brito PF, Gomide M, Câmara VM. Agrotóxicos e saúde: realidade e desafios para mudança de práticas na agricultura. Physis 2009; 19(1):207-225.

40. Faria NMX, Rosa JAR, Facchini LA. Intoxicações por agrotóxicos entre trabalhadores rurais de fruticultura, Bento Gonçalves, RS. Rev Saude Publica 2009; 43(2):335-344.

41. Bedor CNG, Ramos LO, Pereira PJ, Rêgo MAV, Pavão AC, Augusto LGS. Vulnerabilidades e situações de riscos relacionados ao uso de agrotóxicos na fruticultura irrigada. Rev Bras Epidemiol 2009; 12(1):39-49.

42. Alves SMF, Fernandes PM, Reis EF. Análise de correspondência como instrumento para descrição do perfil do trabalhador da cultura de tomate de mesa em Goiás. Cien Rural 2009; 39(7):2042-2049.

43. Marques CRG, Neves PMOJ, Ventura MU. Diagnóstico do conhecimento de informações básicas para o uso de agrotóxicos por produtores de hortaliças da Região de Londrina. Semina: Cien Agrar 2010; 31(3):547-556.

44. Preza DLC, Augusto LGS. Vulnerabilidades de trabalhadores rurais frente ao uso de agrotóxicos na produção de hortaliças em região do Nordeste do Brasil. Rev bras Saude ocup 2012; 37(125):89-98.

45. Cabral ERM. Exposição aos agrotóxicos: implicações na saúde de trabalhadores agrícolas de uma região de Campinas-SP [dissertação]. Campinas: Universidade Estadual de Campinas; 2012.

46. Gonçalves GMS, Gurgel IGD, Costa AM, Almeida LR, Lima TFP, Silva E. Uso de agrotóxicos e a relação com a saúde na etnia Xukuru do Ororubá, Pernambuco, Brasil. Saude Soc 2012; 21(4):1001-1012.

47. Santana VS, Moura MCP, Nogueira FF. Mortalidade por intoxicação ocupacional relacionada a agrotóxicos, 2000-2009, Brasil. Rev Saude Publica 2013; 47(3):598606.
48. Salvi RM, Lara DR, Ghisolfi ES, Portela LV, Dias RD, Souza DO. Neuropsychiatric evaluation in subjects chronically exposed to organophosphate pesticides. Toxicol Sci 2003; 72(2):267-271.

49. Pires DX, Caldas ED, Recena MCP. Intoxicações provocadas por agrotóxicos de uso agrícola na microrregião de Dourados, Mato Grosso do Sul, Brasil, no período de 1992 a 2002. Cad Saude Publica 2005; 21(3):804-814.

50. Neves PDM, Bellini M. Intoxicações por agrotóxicos na mesorregião norte central paranaense, Brasil - 2002 a 2011. Cien Saude Colet 2013; 18(11):3147-3156.

51. Chrisman JR, Koifman S, Sarcinelli PN, Moreira JC, Koifman RJ, Meyer A. Pesticide sales and adult male cancer mortality in Brazil. Int J Hyg Environ Health 2009; 212(3):310-321.

52. Araújo ACP, Nogueira DP, Augusto LGS. Impacto dos praguicidas na saúde: estudo da cultura de tomate. Rev Saude Publica. 2000; 34(3):309-313.

53. Moreira JC, Jacob SC, Peres F, Lima JS, Meyer A, Oliveira-Silva JJ, Sarcinelli PN, Batista DF, Egler M, Castro Faria MV, Araújo AJ, Kubota AH, Soares MO, Alves SR, Moura CM, Curi R. Avaliação integrada do impacto do uso de agrotóxicos sobre a saúde humana em uma comunidade agrícola de Nova Friburgo, RJ. Cien Saude Colet 2002; 7(2):299-211.

54. Delgado IF, Paumgartten FJR. Intoxicações e uso de pesticidas por agricultores do Município de Paty do Alferes, Rio de Janeiro, Brasil. Cad Saude Coletiva 2004; 20(1):180-186.

55. Gomide M. Agrotóxico: que nome dar? Cien Saude Colet 2005; 10(4):1047-1054.

56. Fonseca MGU, Peres F, Firmo JOA, Uchôa E. Percepção de risco: maneiras de pensar e agir no manejo de agrotóxicos. Cien Saude Colet 2007; 12(1):39-50.

57. Araújo AJ, Lima JS, Moreira JC, Jacob SC, Soares MO, Monteiro MCM, Amaral AM, Kubota A, Meyer A, Cosenza CAN, Neves C, Markowitz S. Exposição múltipla a agrotóxicos e efeitos à saúde: estudo transversal em amostra de 102 trabalhadores rurais, Nova Friburgo, RJ. Cien Saude Colet 2007; 12(1):115-130.

58. Recena MCP, Caldas ED. Percepção de risco, atitudes e práticas no uso de agrotóxicos entre agricultores de Culturama, MS. Rev Saude Publica 2008; 42(2):294301.

59. Gregolis TBL, Pinto WJ, Peres F. Percepção de riscos do uso de agrotóxicos por trabalhadores da agricultura familiar do município de Rio Branco, AC. Rev bras Saude ocup 2012; 37(125):99-113.

60. Júnior EEF, Souza KR, Renovato RD, Sales CM. Relações de saúde e trabalho em assentamento rural do MST na região de fronteira Brasil-Paraguai. Trab Educ Saude 2012; 9(3):379-397.

61. Silva JPL, Araújo MZ, Melo LCQ. Panorama da vulnerabilidade da saúde do agricultor familiar de São José de Princesa/PB. Rev bras cien Saude 2013; 17(1):29-38.

Artigo apresentado em 07/07/2014

Aprovado em 11/07/2014

Versão final apresentada em 12/07/2014 